\title{
Article \\ Robust Stability Analysis of Unstable Second Order Plus Time-Delay (SOPTD) Plant by Fractional-Order Proportional Integral (FOPI) Controllers
}

\author{
Marzieh Asadi ${ }^{1}$, Arash Farnam ${ }^{2,3, *}$, Hamed Nazifi ${ }^{4}\left(\mathbb{D}\right.$, Sam Roozbehani $^{4}$ and Guillaume Crevecoeur ${ }^{2,3} \mathbb{D}$ \\ 1 Faculty of Electerical Engineering, K.N. Toosi University of Technology, Tehran 19697, Iran; \\ mr89asadi@alumni.kntu.ac.ir \\ 2 Department of Electrical Energy, Metals, Mechanical Constructions and Systems, Ghent University, \\ 9000 Ghent, Belgium; guillaume.crevecoeur@ugent.be \\ 3 Core Lab EEDT Decision and Control, Flanders Make, 3920 Lommel, Belgium \\ 4 Renewable Power Generation Research Group, Khaje Nasir University of Technology Branch, ACECR, \\ Tehran 19697, Iran; nazifi@acecr.ac.ir (H.N.); samroozbehani@acecr.ac.ir (S.R.) \\ * Correspondence: arash.farnam@ugent.be
}

check for updates

Citation: Asadi, M.; Farnam, A.;

Nazifi, H.; Roozbehani, S.;

Crevecoeur, G. Robust Stability Analysis of Unstable Second Order Plus Time-Delay (SOPTD) Plant by Fractional-Order Proportional Integral (FOPI) Controllers. Mathematics 2022, 10, 567. https:// doi.org/10.3390/math10040567

Academic Editor: António Mendes Lopes

Received: 13 January 2022

Accepted: 10 February 2022

Published: 12 February 2022

Publisher's Note: MDPI stays neutral with regard to jurisdictional claims in published maps and institutional affiliations.

Copyright: (C) 2022 by the authors. Licensee MDPI, Basel, Switzerland. This article is an open access article distributed under the terms and conditions of the Creative Commons Attribution (CC BY) license (https:// creativecommons.org/licenses/by/ $4.0 /)$.

\begin{abstract}
This study investigates the robust stability analysis of an unstable second order plus timedelay (SOPTD) plant by using Fractional-Order Proportional Integral (FOPI) controllers. We assume that there are simultaneous uncertainties in gain, time-constants, and time-delay of the plant. At first, a graphical method is provided for a robust stability analysis of the closed-loop system. Then, a robust stability checking function is introduced to facilitate the robust stability analysis. Additionally, new bounds are presented to reduce the computational burden for the robust stability analysis. Finally, two examples are provided to show the correctness of the proposed method.
\end{abstract}

Keywords: robust stability analysis; FOPI controllers; unstable SOPTD plants; time-delay

\section{Introduction}

Generally, many real-world systems can be modeled by time-delay transfer functions because the dead time is inevitable and appears in real systems [1]. In practical applications, it was shown that the delay may also contain an interval uncertainty [1-3]. Moreover, it has been shown that fractional-order controllers provide more flexibility compared with integerorder controllers [4]. This can be attributed to the extra parameters within fractional-order controllers [5,6]. Therefore, much attention has been paid to design robust fractional-order controllers for fractional-order nonlinear time-delayed systems $[7,8]$ and fractional-order linear time-delayed systems $[9,10]$.

Stability analysis is fundamental to any control system. Hence, some methods have been proposed to analyze the stability of LTI fractional-order systems in [11-16]. Lately, the value set-based approach has attracted many researchers to check the robust stability of LTI systems. In $[17,18]$, the value set approach has been provided for robust stability analysis of LTI fractional-order systems having time delay. The works of $[19,20]$ have proven that the value set of fractional-order systems of incommensurate and commensurate orders possessing uncertain coefficients is a parpolygon in the complex plane. Inspired by the results presented in $[17,19,20]$, some value set-based approaches have been presented to inspect the robust stability of fractional-order plants by linear fractional-order controllers in $[21,22]$.

In [23,24], Fractional-Order Proportional Integral Derivative (FOPID) controllers were designed to improve the robustness property of first order in addition to dead time systems. Then, in $[25,26]$, some auxiliary functions have been presented for robust stability analysis of interval fractional order systems having time-delay. Moreover, in [27], a graphical tuning method has been proposed to determine the stabilizing regions of FOPI controllers for 
fractional systems with time-delays by benefiting from the D-decomposition technique. Moreover, in $[28,29]$, new methods were introduced to design controllers for systems suffering from time-delay.

This study develops the robust stability analysis of an unstable Second Order Plus timedelay (SOPTD) plant by FOPI controllers. In [30-32], some methods have been proposed to design various controllers. However, the methods presented in [30-32] cannot ensure the robust stability of the closed-loop system in the presence of plant uncertainties in time-delay, gain, and time constants. This issue has prompted the authors of this paper to present a simple method to analyze the robust stability of a closed-loop system consisting of unstable SOPTD plants and FOPI controllers. The contributions and novelties of this paper are mainly summarized as follows:

- Robust stability analysis of a closed-loop control system consisting of unstable SOPTD planst and FOPI controllers;

- Introducing a frequency range for reducing computational burden;

- Presenting a robust stability checking function for robust stability analysis of the closed-loop system.

The remainder of this study is organized as follows: Section 2 reviews preliminaries. Section 3 presents the main results. In Section 4, two examples are provided for demonstration. Finally, Section 5 concludes the paper.

\section{Background and Preliminaries}

Among most popular definitions proposed for fractional-order differentiation, Caputo fractional-order derivative is mainly employed and is defined as follows ([33]):

$$
{ }_{a}^{C} D_{t}^{\gamma} x(t)=\frac{1}{\Gamma(n-\gamma)} \int_{a}^{t} \frac{x^{n}(\tau)}{(t-\tau)^{\gamma-n+1}} d \tau,
$$

in which $\gamma(n-1<\gamma<n)$, and $n$ is an integer number. In (1), $\Gamma$ is the Euler's Gamma function. $a$ and $t$ are the terminals of the integral. Based on the explanations presented in [33], the Laplace transform of the Caputo's fractional-order derivative can be given by the following:

$$
L\left[{ }_{a}^{C} D_{t}^{\gamma} x(t)\right]=s^{\gamma} L[x(t)]-\sum_{i=0}^{n-1} s^{\gamma-i-1} x^{i}(0)
$$

for the zero initial conditions can be simplified as follows.

$$
\left.L{ }_{a}^{C} D_{t}^{\gamma} x(t)\right]=s^{\gamma} L[x(t)]
$$

Hence, the transfer function of an FOPI controller can be obtained as follows.

$$
C(s)=K_{p}+\frac{K_{i}}{s^{\lambda}}, 0<\lambda<2
$$

Moreover, the unstable SOPTD plant is considered as follows:

$$
P(s)=\frac{K}{\left(T_{1} s-1\right)\left(T_{2} s+1\right)} e^{-L s}
$$

in which $K$ is the gain lying in the interval $0<K^{-} \leq K \leq K^{+}$; $T_{1}$ and $T_{2}$ are time constants within the intervals $0<T_{1}^{-} \leq T_{1} \leq T_{1}^{+}$and $0<T_{2}^{-} \leq T_{2} \leq T_{2}^{+}$; and $L$ is the time-delay lying in interval $0<L^{-} \leq L \leq L^{+}$.

The characteristic function for the FOPI controller $C(s)$ in (4) and the plant $P(s)$ in (5) can be considered as $\Delta(s)$ in (6):

$$
\Delta(s)=\Delta_{1}(s)+\Delta_{2}(s)
$$


in which the following is the case.

$$
\begin{array}{r}
\Delta_{1}(s)=\left(T_{1} s-1\right)\left(T_{2} s+1\right) s^{\lambda}, \\
\Delta_{2}(s)=K\left(K_{p} s^{\lambda}+K_{i}\right) e^{-L s}
\end{array}
$$

Based on the above explanations, the following design problem is formulated.

Problem 1: Develop efficient methods to investigate the robust stability of the closedloop system with characteristic function $\Delta(s)$ in (6).

Our main results are based on the following principle called the Zero Exclusion Principle.

Zero Exclusion Principle [17]: The closed-loop control system can be robustly stabilized by the FOPI controller $C(s)$ in (4) if and only if $\Delta(s)$ contains one stable member and $0 \notin \Delta(j \omega)$ for $\omega \geq 0$.

\section{Main Results}

By the zero exclusion principle, the position relationship between the origin and the value set of $\Delta(j \omega)$ has to be investigated for $\omega \geq 0$. Therefore, in Theorem 1, a frequency range is obtained instead of $[0, \infty)$ for reducing the computational cost.

Theorem 1. The origin is not contained in the value set of $\Delta(j \omega)$ for the frequency interval $\omega \in\left(\omega_{\max }, \infty\right)$, where $\omega_{\max }$ is obtained as follows.

$$
\begin{aligned}
& \omega_{\max } \triangleq \max \{1, \sigma\} \\
& \sigma \triangleq \frac{T_{1}^{+}+T_{2}^{+}+1+K^{+}\left(\left|K_{p}\right|+\left|K_{i}\right|\right)}{T_{1}^{-} T_{2}^{-}}
\end{aligned}
$$

Proof. Inequality $|\Delta(j \omega)|>0$ guarantees that $0 \notin \Delta(j \omega)$. Accordingly, by benefiting from the triangle inequality and assuming $\omega>1$, one has the following.

$$
\begin{aligned}
& |\Delta(j \omega)| \geq T_{1}^{-} T_{2}^{-} \omega^{2+\lambda}- \\
& \left(\left(T_{1}^{+}+T_{2}^{+}\right) \omega^{1+\lambda}+\omega^{\lambda}+k^{+}\left(\left|K_{p}\right| \omega^{\lambda}+\left|K_{i}\right|\right)\right)
\end{aligned}
$$

Due to $|\omega|>1$, the following inequalities hold.

$$
\omega^{2+\lambda}>\omega^{1+\lambda}>\cdots>\omega^{0}
$$

Regarding (9) and (10), the following inequality can be derived.

$$
\begin{aligned}
& |F(j \omega)| \geq T_{1}^{-} T_{2}^{-} \omega^{2+\lambda}- \\
& \left(\left(T_{1}^{+}+T_{2}^{+}\right) \omega^{1+\lambda}+\omega^{\lambda}+K^{+}\left(\left|K_{p}\right| \omega^{\lambda}+\left|K_{i}\right|\right)\right) \geq T_{1}^{-} T_{2}^{-} \\
& \omega^{1+\lambda}\left(\omega^{1}-\left(\left(T_{1}^{+}+T_{2}^{+}\right)+1+K^{+}\left(\left|K_{p}\right|+\left|K_{i}\right|\right)\right)\right)
\end{aligned}
$$

It is apparent that $T_{1}^{-} T_{2}^{-} \omega^{1+\lambda}>0$. Accordingly, $\omega>\sigma$ ensures inequality $|\Delta(j \omega)|>0$, where $\sigma$ is defined in (8).

Based on the zero exclusion principle, it is important to check whether or not $0 \in \Delta(j \omega)$ in (6) for $\omega \geq 0$. Therefore, the next theorem presents a graphical method to check the distance between the origin and the value set of $\Delta(j \omega)$ in (6) for $0 \leq \omega \leq \omega_{\max }$.

Theorem 2. $0 \notin \Delta(j \omega)$ in (6) for $0 \leq \omega \leq \omega_{\max }$, if the value sets of $-\Delta_{1}(j \omega)$ and $\Delta_{2}(j \omega)$ do not have any overlap in the complex plane. 
Proof. It is assumed that $-\Delta_{1}\left(j \omega_{0}\right)$ and $\Delta_{2}\left(j \omega_{0}\right)$ have an overlap. Therefore, there is a complex number such as $Z_{0} \in \mathbb{C}$ such that $z_{0} \in-\Delta_{1}\left(j \omega_{0}\right)$ and $z_{0} \in \Delta_{2}\left(j \omega_{0}\right)$. It implies that a member of $-\Delta_{1}\left(j \omega_{0}\right)$ as $-\tilde{\Delta}_{1}\left(j \omega_{0}\right)$, equaling to $z_{0}$, i.e., $z_{0}=-\tilde{\Delta}_{1}\left(j \omega_{0}\right)$. It is clear that $z_{0}=\tilde{\Delta}_{2}\left(j \omega_{0}\right)$ or $z_{0}=\tilde{\Delta}_{2}\left(j \omega_{0}\right)$. Consider $\left\{\tilde{\Delta}(j \omega)=\tilde{\Delta}_{1}(j \omega)+\tilde{\Delta}_{2}(j \omega)\right\} \in \Delta(j \omega)$. Accordingly, at $\omega=\omega_{0}$, it is visible that $0 \in \Delta(j \omega)$. Therefore, if $-\Delta_{1}(j \omega)$ and $\Delta_{2}(j \omega)$ have no overlap in the complex plane, then $0 \notin \Delta(j \omega)$.

Now, by using Theorem 2 and the zero exclusion principle, the following lemma presents a graphical procedure to check the robust stability of $\Delta(s)$ in (6).

Lemma 1. Assume that a nominal characteristic function of $\Delta(s)$ in (6) as $\hat{\Delta}(s)$ is stable. Then, $\Delta(s)$ in (6) is robust stable, if $\Delta_{1}^{b}(\omega)$ in (12) and $\Delta_{2}^{b}(\omega)$ in (13) do not have an overlap in the complex plane for $\omega \in\left[0, \omega_{\max }\right]$.

$$
\begin{aligned}
& \Delta_{1}^{b}(\omega)=\left\{e_{i} \mid i=1,2,3,4\right\} \\
& e_{i}=\left\{\eta v_{i}+(1-\eta) v_{i+1} \mid \eta \in[0,1]\right\} \\
& v_{1}=v_{5}=-\left(T_{1}^{+} T_{2}^{+}(j \omega)^{2}+\min \left\{T_{1}-T_{2}\right\} j \omega-1\right)(j \omega)^{\lambda} \\
& v_{2}=-\left(T_{1}^{-} T_{2}^{-}(j \omega)^{2}+\min \left\{T_{1}-T_{2}\right\}(j \omega)-1\right)(j \omega)^{\lambda} \\
& v_{3}=-\left(T_{1}^{-} T_{2}^{-}(j \omega)^{2}+\max \left\{T_{1}-T_{2}\right\}(j \omega)-1\right)(j \omega)^{\lambda} \\
& v_{4}=-\left(T_{1}^{+} T_{2}^{+}(j \omega)^{2}+\max \left\{T_{1}-T_{2}\right\}(j \omega)-1\right)(j \omega)^{\lambda} \\
& \Delta_{2}^{b}(\omega)=
\end{aligned}
$$

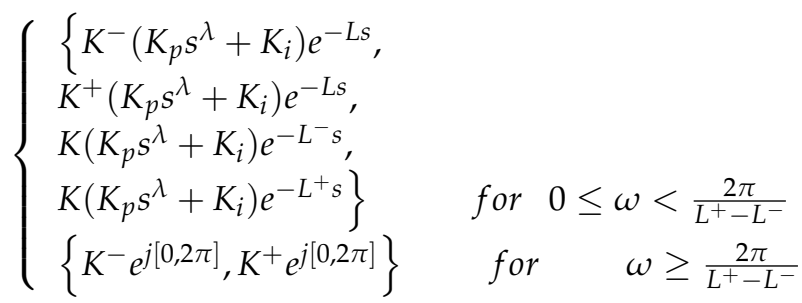

Proof. Based on Theorem 1, $0 \notin \Delta(j \omega)$ in (6) for $\omega>\omega_{\max }$. Therefore, regarding Theorem 2, we only check the overlap between $-\Delta_{1}(j \omega)$ and $\Delta_{2}(j \omega)$ for $\omega \in\left[0, \omega_{\max }\right]$. On the other hand, based on the results obtained in [19], $\Delta_{1}^{b}(\omega)$ shows the boundary of the value set of $-\Delta_{1}(j \omega)$. Moreover, it is obvious that $\Delta_{2}^{b}(\omega)$ also depicts the boundary of the value set of $\Delta_{2}(j \omega)$. Therefore, if $\Delta_{1}^{b}(\omega)$ and $\Delta_{2}^{b}(\omega)$ do not have the overlap for $\omega \in\left[0, \omega_{\max }\right]$, then the value sets of $-\Delta_{1}(j \omega)$ and $\Delta_{2}(j \omega)$ do not have any overlap for $\omega \in\left[0, \omega_{\max }\right]$ according to Theorem 2 . Therefore, the zero exclusion principle completes the proof.

Generally, the graphical method presented in Lemma 1 for robust stability analysis may be difficult, since we have to plot value sets $\Delta_{1}^{b}(\omega)$ in (12) and $\Delta_{2}^{b}(\omega)$ in (13) at each frequency. Hence, in the next theorem, a robust stability checking function is offered in order to easily inspect the overlap between $\Delta_{1}^{b}(\omega)$ in (12) and $\Delta_{2}^{b}(\omega)$ in (13).

Theorem 3. Assume that a nominal characteristic function of $\Delta(s)$ in (6) as $\hat{\Delta}(s)$ is stable. Then, the characteristic function $\Delta(s)$ in (6) is robust and stable, if the inequality $D(\omega)>0$ in (14) holds for $\omega \in\left[0, \omega_{\max }\right]$ :

$$
D(\omega)=\left\{\begin{array}{lrr}
D_{1}(\omega) & \text { for } & 0 \leq \omega<\frac{2 \pi}{L^{+}-L^{-}} \\
D_{2}(\omega) & \text { for } & \omega \geq \frac{2 \pi}{L^{+}-L^{-}}
\end{array}\right.
$$


in which the following is the case:

$$
\begin{aligned}
& D_{1}(\omega)=\min \left\{D_{1}^{N}, D_{1}^{D}\right\} \\
& D_{1}^{D}= \\
& \min \left\{D_{h, g}^{D}(j \omega) \mid h \in\{1, \cdots, 4\}, g \in\{1, \cdots, 4 N+2\}\right\}, \\
& D_{h, g}^{D}(j \omega)=\left|v_{h+1}(j \omega)+H_{g}(j \omega)\right|+\left|v_{h}(j \omega)+H_{g}(j \omega)\right| \\
& -\left|v_{h}(j \omega)-v_{h+1}(j \omega)\right| \text {, } \\
& D_{1}^{N}= \\
& \min \left\{D_{h, g}^{N}(j \omega) \mid h \in\{1, \cdots, 4\}, g \in\{1, \cdots, 4 N+2\}\right\}, \\
& D_{h, g}^{N}(j \omega)=\left|v_{h}(j \omega)+H_{g}(j \omega)\right|+\left|v_{h}(j \omega)+H_{g+1}(j \omega)\right| \\
& -\left|H_{g}(j \omega)-H_{g+1}(j \omega)\right| \text {, } \\
& D_{2}(\omega) \triangleq \min _{e_{i} \in \Delta_{1}^{b}(\omega)}\left|e_{i}\right|-\left|K^{+}\left(K_{p}(j \omega)^{\lambda}+K_{i}\right)\right| \\
& H_{g}(j \omega) \triangleq \begin{cases}\bar{P}_{(g-1)}(j \omega), & \text { for } 1 \leq g \leq 2 N+1, \\
\underline{P}_{(2 N)}(j \omega), & \text { for } g=2 N+2, \\
\underline{P}_{(2 N-1)}(j \omega), & \text { for } g=2 N+3, \\
\vdots & \text { for } g=4 N+2, \\
\bar{P}_{0}(j \omega), & \text { for } g=4 N+3,\end{cases} \\
& \bar{P}_{h}(j \omega) \triangleq \\
& \left\{\begin{array}{l}
K^{+}\left(K_{p} s^{\lambda}+K_{i}\right) \mathrm{e}^{-j \omega\left(L^{-}+h \frac{L^{+}-L^{-}}{2 N}\right)}, \text { for } h=0,2, \cdots, 2 N \\
\frac{K^{+}\left(K_{p} s^{\lambda}+K_{i}\right) \mathrm{e}^{-j \omega\left(L^{-}+h \frac{L^{+}-L^{-}}{2 N}\right)}}{\cos \left(\omega \frac{L^{+}-L^{-}}{2 N}\right)}, \text { for } h=1,3, \cdots, 2 N-1
\end{array}\right. \\
& \underline{P}_{h}(j \omega) \triangleq K^{-}\left(K_{p} s^{\lambda}+K_{i}\right) \mathrm{e}^{-j \omega\left(L^{-}+h \frac{L^{+}-L^{-}}{2 N}\right)} \\
& h=0,1,2, \cdots, 2 N
\end{aligned}
$$

where $N$ is an arbitrary number and $N \in \mathbb{N} \geq 3$.

Proof. Figure 1 depicts the value set of $K\left(K_{p} s^{\lambda}+K_{i}\right) e^{-L s}$ and the vertices $\bar{P}_{h}(s)$ and $\underline{P}_{h}(s)$ for $s=j \omega, \omega \in\left[0, \frac{2 \pi}{L^{+}-L^{-}}\right)$. As it is seen from Figure 1 , the value set of $\Delta_{2}(j \omega)$ is located inside of $H_{g}(j \omega)$. If it is proven that in the complex plane, the value sets of $-\Delta_{1}(j \omega)$ and $H_{g}(j \omega)$ do not have any overlap, then based on Lemma 1, it can be concluded that this system is robust stable.

It is obvious that the triangle inequality holds for two consecutive vertices of $-\Delta_{1}(j \omega)$ and any vertices of $H_{g}(j \omega)$, then no vertices of $H_{g}(j \omega)$ intersect $-\Delta_{1}(j \omega)$. Moreover, if the inequality $D_{h, g}^{N}(j \omega)>0$ holds, then no vertices of $-\Delta_{1}(j \omega)$ intersect $H_{g}(j \omega)$. Therefore, in the complex plane, the value sets of $-\Delta_{1}(j \omega)$ and $H_{g}(j \omega)$ do not have any overlap for $\omega \in\left[0, \frac{2 \pi}{L^{+}-L^{-}}\right)$. Furthermore, for $\omega \in\left[\frac{2 \pi}{L^{+}-L^{-}}, \omega_{\max }\right]$, it is apparent that if inequality $D_{2}(\omega)$ is held, then $0 \notin \Delta(j \omega)$. Accordingly, based on Lemma 1 and the zero exclusion principle, the proof can be simply completed. 


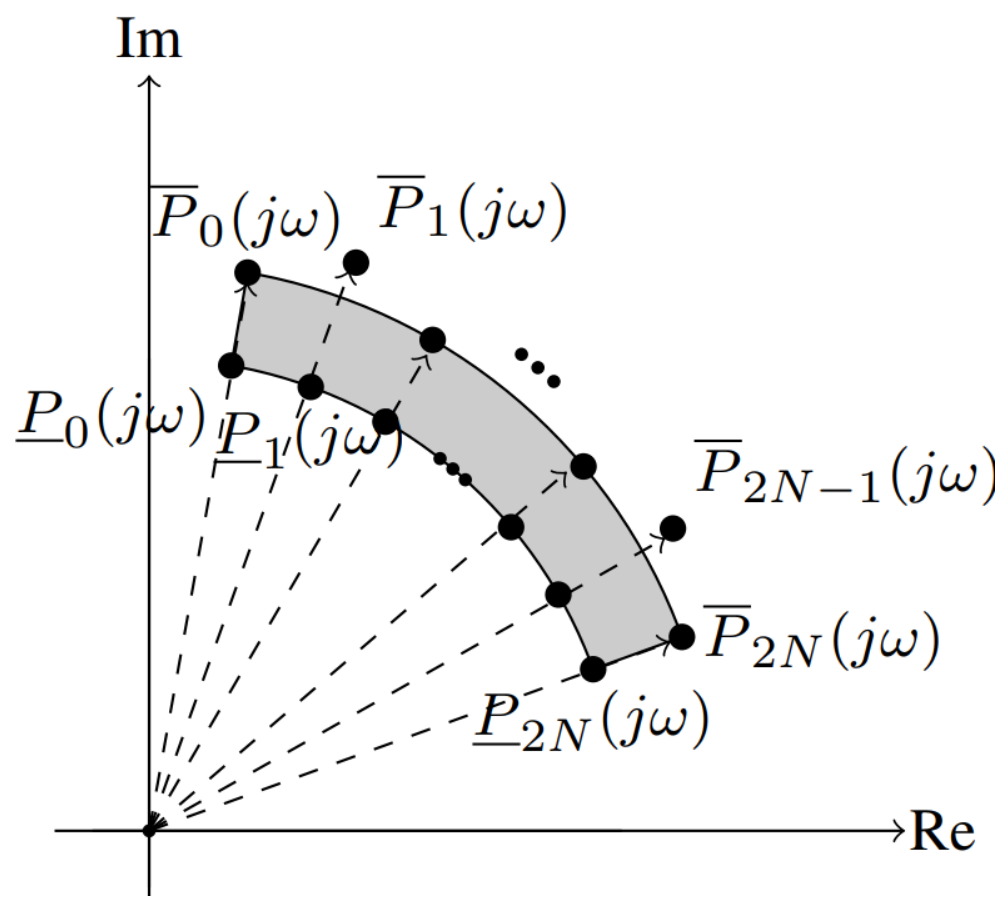

Figure 1. The value set of $\Delta_{2}(j \omega)$ and the vertices $\bar{P}_{h}(j \omega)$ and $\underline{P}_{h}(j \omega)$.

Remark 1. The robust stability of $\Delta(j \omega)$ can be checked by performing the following steps:

1. Check the stability of one arbitrary member of $\Delta(s)$ as $\hat{\Delta}(s)$. If $\hat{\Delta}(s)$ is not robust stable, then clearly $\Delta(s)$ is not robust stable. Otherwise, continue the following step;

2. Calculate the value of $\omega_{\max }$ presented in Theorem 1;

3. Check the sign of $D(\omega)$ in Theorem 3 for $\omega \in\left[0, \omega_{\max }\right] \mathrm{rad} / \mathrm{s} . \Delta(\mathrm{s})$ would be robust stable when the inequality $D(\omega)>0$ is held for $\omega \in\left[0, \omega_{\max }\right] \mathrm{rad} / \mathrm{s}$.

\section{Illustrative Examples}

In this Section, two examples show the use of the obtained results.

Example 1. Consider of the following unstable plant discussed in [32].

$$
P(s)=\frac{1}{(2 s-1)(s+1)} e^{-0.3 s}
$$

Let us consider the plant $P(s)$ in (16) as an uncertain plant in (17).

$$
P(s)=\frac{[0.9,1.1]}{([0.8,1.2] s+1)([1.8,2.2] s-1)} e^{-[0.2,0.4] s}
$$

In the following, it is shown that FOPI controller $C(s)=2+0.02 / s^{0.1}$ can robustly stabilize the closed-loop system. The approach proposed in [12] is employed to check the stability of $\hat{\Delta}(s)$ in (18). Based on [12] and Figure 2, it can be concluded that $\hat{\Delta}(s)$ is stable, since, in the complex plane, $\psi(j \omega)$ in (19) does not encircle the origin.

$$
\begin{gathered}
\hat{\Delta}(s)=s^{0.1}(s+1)(2 s-1)+\left(0.02+2 s^{0.1}\right) e^{-0.3 s} \\
\psi(s)=\frac{\hat{\Delta}(s)}{2(s+1)^{2.1}}, s=j \omega .
\end{gathered}
$$

Moreover from Theorem 1, one can obtain $\omega_{\max }=4.7361 \mathrm{rad} / \mathrm{s}$. Figure 3 shows the values of the auxiliary function $D(\omega)$ in (14). It is clear that the inequality $D(\omega)>0$ holds for $\omega \in\left[0, \omega_{\max }\right]$. From Figure 3 and Theorem 3, the closed-loop system is robust 
stable. As this example shows, the work in [32] cannot guarantee the robust stability of such systems. On the other hand, the results of the present paper can be used for robust stability analysis of unstable processes having uncertain time delay by FOPI controllers. Moreover, Theorem 1 helps to reduce the computational burden by presenting the upper frequency bound $\omega_{\max }$.

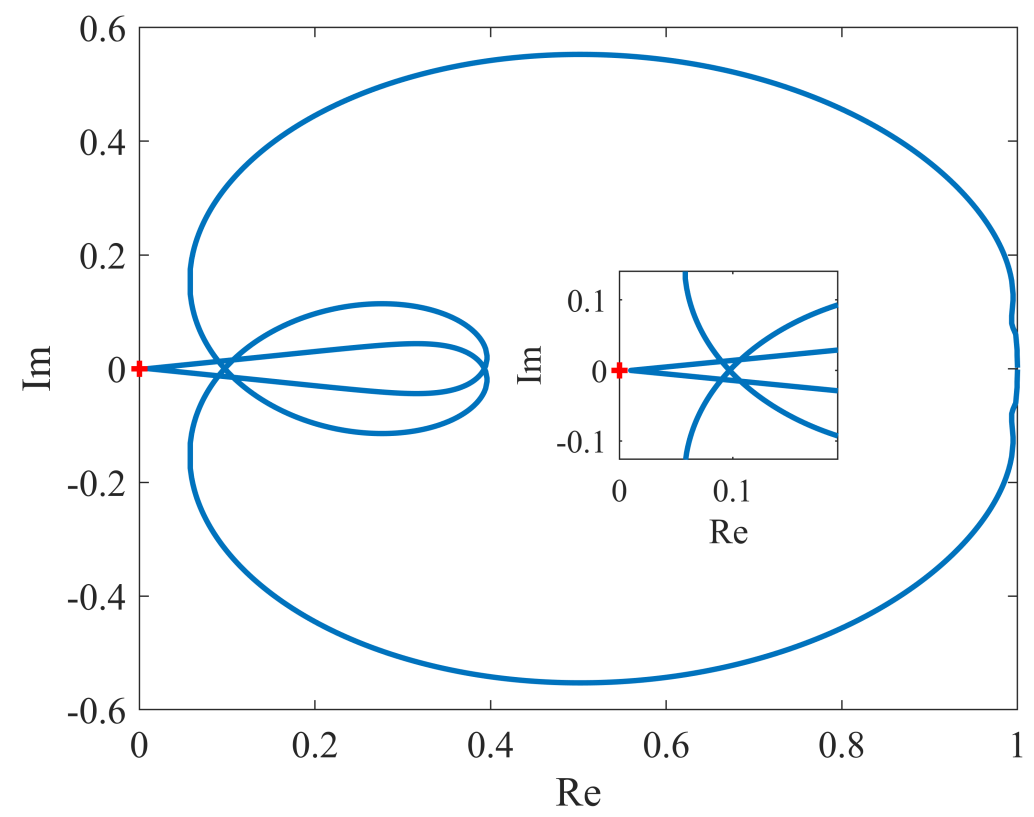

Figure 2. The values of function $\psi(s)$ in (23).

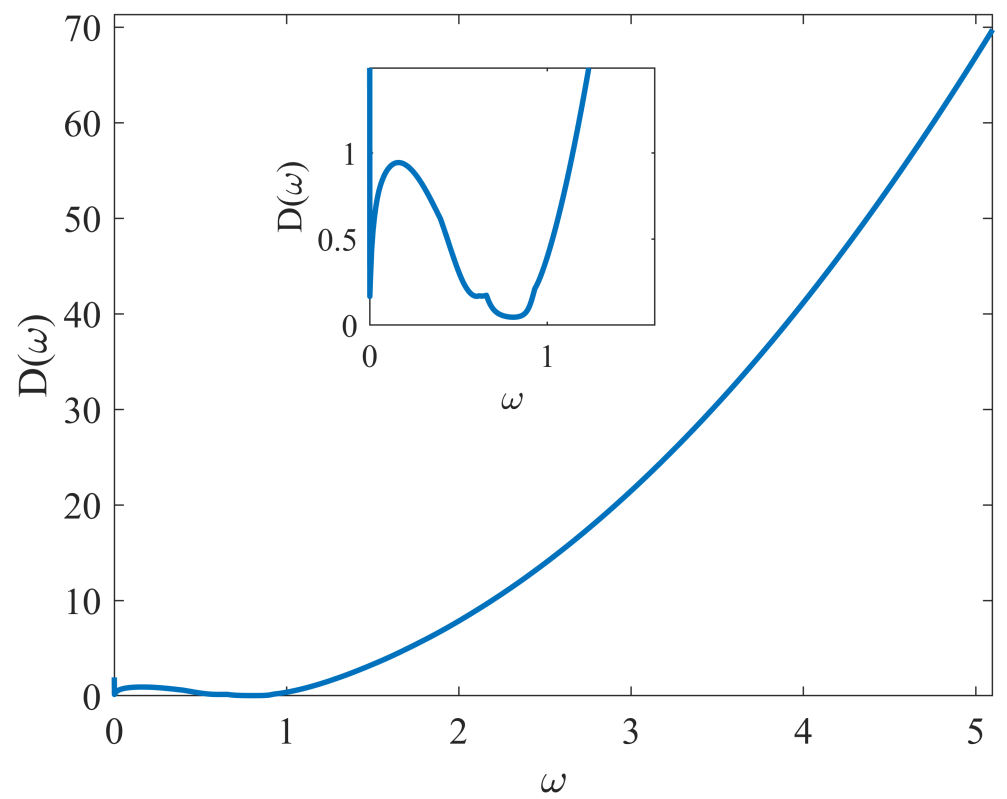

Figure 3. The curve of auxiliary function $D(\omega)$ in (14) for Example 1.

Example 2. Consider the following unstable SOPTD plant:

$$
P(s)=\frac{[0.9,1.1]}{([0.5,1.5] s+1)([990,1100] s-1)} e^{-[0.1,0.2] s}
$$

and an FOPI controller as follows.

$$
C(s)=0.1+\frac{0.2}{s^{0.5}}
$$


Again, the method presented in [12] is used to check the stability of $\hat{\Delta}(s)$ in (22). Figure 4 shows the values of $\psi(j \omega)$ in (23). Based on [12] and Figure 4, it can be deduced that $\hat{\Delta}(s)$ is stable since, in the complex plane, $\psi(j \omega)$ in (23) does not encircle the origin.

$$
\begin{gathered}
\hat{\Delta}(s)=s^{0.5}(s+1)(1000 s-1)+\left(0.1+0.2 s^{0.5}\right) e^{-0.2 s} \\
\psi(s)=\frac{\hat{\Delta}(s)}{1000(s+1)^{2.5}}, s=j \omega .
\end{gathered}
$$

From Theorem 1, one can obtain $\omega_{\max }=1 \mathrm{rad} / \mathrm{s}$. Figure 5 shows the values of auxiliary function $D(\omega)$ in (14). As depicted in this figure, inequality $D(\omega)>0$ holds for $\omega \in\left[0, \omega_{\max }\right]$. From Figure 5 and Theorem 3 , the closed-loop system is robust stable.

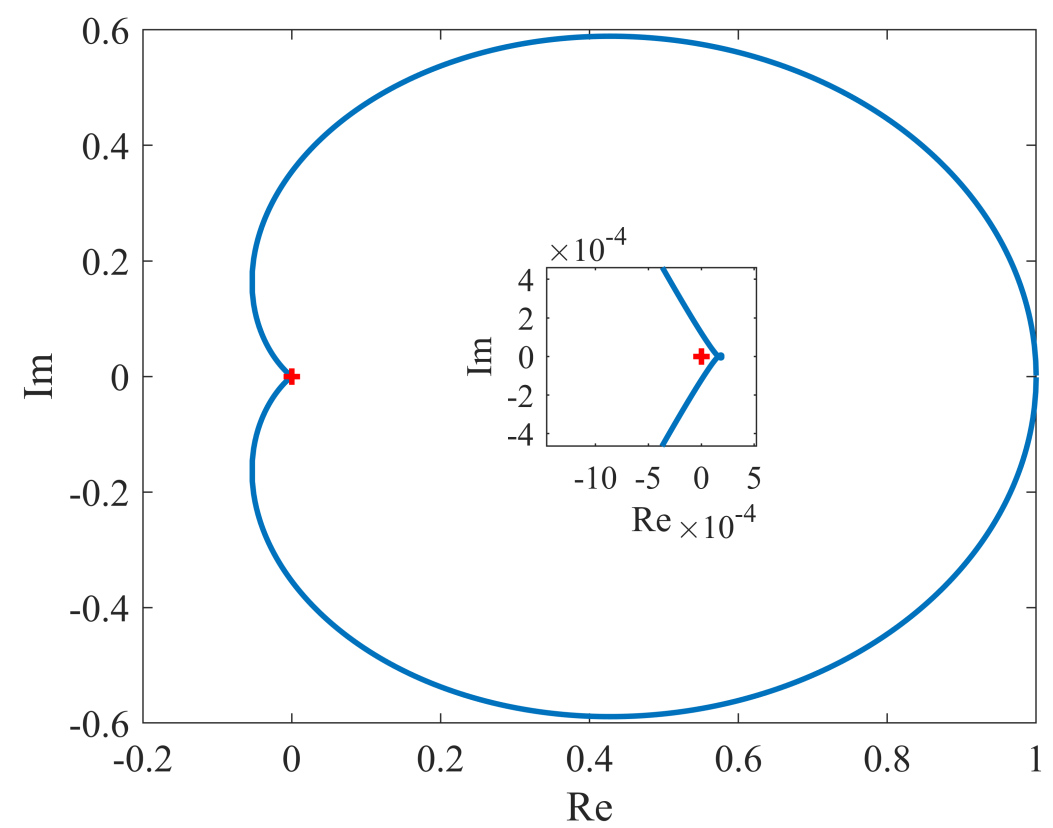

Figure 4. The values of function $\psi(s)$ in (23).

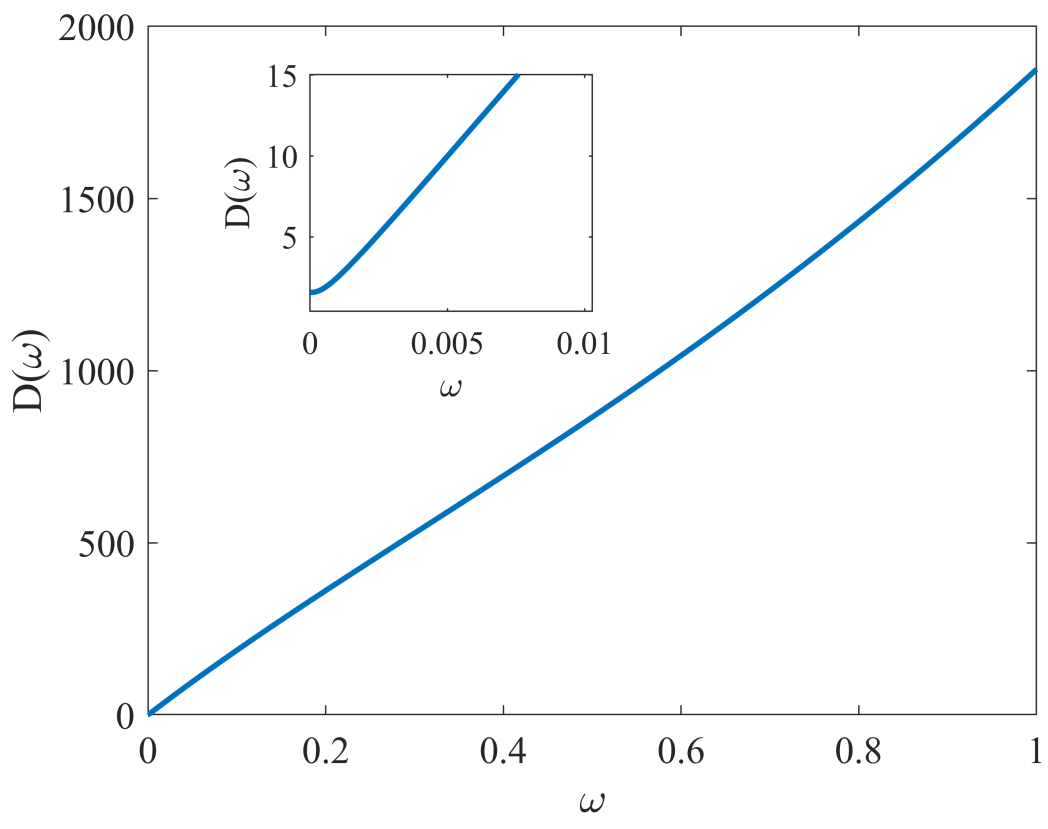

Figure 5. The curve of auxiliary function $D(\omega)$ in (14) for Example 2 . 


\section{Conclusions}

This study was dedicated to check the robust stability of systems consisting of an unstable SOPTD plant and FOPI controllers. Theorem 1 was presented to reduce the computational cost for the robust stability analysis, since, instead of frequency $[0, \infty)$, a robust stability analysis can be performed in $\omega \in\left[0, \omega_{\max }\right]$. Moreover, Lemma 1 was offered to present a graphical method for the robust stability analysis. In Theorem 3, an auxiliary function was provided to investigate robust stability. Moreover, auxiliary function $D(\omega)$ facilitates the process of robust stability analysis. this is because the sign of this function can determine the robust stability of the system. Moreover, two examples were presented to show the effectiveness and simplicity of the results. Future works may include presenting the stabilizing region of FOPI controllers for such systems having uncertain time delays.

Author Contributions: Conceptualization, M.A.; Writing-review and editing, A.F., H.N., S.R. and G.C. All authors have read and agreed to the published version of the manuscript.

Funding: This work was supported by the Flanders Make SBO project DIRAC.

Institutional Review Board Statement: Not applicable.

Informed Consent Statement: Not applicable.

Data Availability Statement: Not applicable.

Conflicts of Interest: The authors declare no conflict of interest.

\section{References}

1. Ghorbani, M.; Tavakoli-Kakhki, M.; Estarami, A.A. Robust FOPID stabilization of retarded type fractional order plants with interval uncertainties and interval time delay. J. Frankl. Inst. 2019, 356, 9302-9329. [CrossRef]

2. Lee, T.H.; Wang, Q.G.; Tan, K.K. Robust Smith-predictor controller for uncertain delay systems. AIChE J. 1996, 42, 1033-1040. [CrossRef]

3. Feliu-Batlle, V.; Pérez, R.R.; García, F.J.C.; Rodriguez, L.S. Smith predictor based robust fractional order control: Application to water distribution in a main irrigation canal pool. J. Process Control. 2019, 19, 506-519. [CrossRef]

4. Podlubny, I. Fractional-order systems and PI/sup/spl lambda//D/sup/spl mu//-controllers. IEEE Trans. Autom. Control. 1999, 44, 208-214. [CrossRef]

5. Moornani, K.A.; Haeri, M. Robust stability check for fractional PID-based control systems. Trans. Inst. Meas. Control. 2013, 35, 236-246. [CrossRef]

6. Tepljakov, A.; Alagoz, B.B.; Yeroglu, C.; Gonzalez, E.A.; Hosseinnia, S.H.; Petlenkov, E.; Ates, A.; Cech, M. Towards Industrialization of FOPID Controllers: A Survey on Milestones of Fractional-Order Control and Pathways for Future Developments. IEEE Access 2021, 9, 21016-21042. [CrossRef]

7. Wang, Z.; Wang, X.; Xia, J.; Shen, H.; Meng, B. Adaptive sliding mode output tracking control based-FODOB for a class of uncertain fractional-order nonlinear time-delayed systems. Sci. China Technol. Sci. 2020, 63, 1854-1862. [CrossRef]

8. Meng, B.; Wang, X.; Zhang, Z.; Wang, Z. Necessary and sufficient conditions for normalization and sliding mode control of singular fractional-order systems with uncertainties. Sci. China Inf. Sci. 2020, 63, 1-10. [CrossRef]

9. Boudana, M.; Ladaci, S.; Loiseau, J.J. Fractional Order PI $\mathrm{D} \mu \mu$ Control Design for a Class of Cyber-Physical Systems with Fractional Order Time-Delay models: Fractional PI $\lambda \mathrm{D} \mu$ Design for CPS with Time-Delay models. Int. J. Cyber-Phys. Syst. (IJCPS) 2019, 1, 1-18. [CrossRef]

10. Bouyedda, H.; Ladaci, S.; Sedraoui, M.; Lashab, M. Identification and Control design for a class of non-minimum Phase dead-time Systems based on fractional-order Smith Predictor and Genetic Algorithm Technique. Int. J. Dyn. Control. 2019, 7, 914-925. [CrossRef]

11. Bonnet, C.; Partington, J.R. Coprime factorizations and stability of fractional differential systems. Syst. Control. Lett. 2000, 41, 167-174. [CrossRef]

12. Busłowicz, M. Stability of linear continuous-time fractional order systems with delays of the retarded type. Bull. Pol. Acad. Sci. Tech. Sci. 2008, 56, 158-163.

13. Moornani, K.A.; Haeri, M. Necessary and sufficient conditions for BIBO-stability of some fractional delay systems of neutral type. IEEE Trans. Autom. Control. 2010, 56, 125-128. [CrossRef]

14. Rivero, M.; Rogosin, S.V.; Tenreiro Machado, J.A.; Trujillo, J.J. Stability of fractional order systems. Math. Probl. Eng. 2013, 2013, 356215. [CrossRef]

15. Mesbahi, A.; Haeri, M. Stability of linear time invariant fractional delay systems of retarded type in the space of delay parameters. Automatica 2013, 49, 1287-1294. [CrossRef] 
16. Ghorbani, M.; Tavakoli-Kakhki, M. Robust stability analysis of uncertain incommensurate fractional order quasi-polynomials in the presence of interval fractional orders and interval coefficients. Trans. Inst. Meas. Control. 2020, 43, 1117-1125. [CrossRef]

17. Moornani, K.A.; Haeri, M. On robust stability of lti fractional-order delay systems of retarded and neutral type. Automatica 2010, 46, 362-368. [CrossRef]

18. Moornani, K.A.; Haeri, M. On robust stability of linear time invariant fractional-order systems with real parametric uncertainties. ISA Trans. 2009, 48, 484-490. [CrossRef]

19. Tan, N.; Özgüven, Ö.F.; Özyetkin, M.M. Robust stability analysis of fractional order interval polynomials. ISA Trans. 2009, 48, 166-172. [CrossRef]

20. Moornani, K.A.; Haeri, M. Robust stability testing function and Kharitonov-like theorem for fractional order interval systems. IET Control. Theory Appl. 2010, 4, 2097-2108. [CrossRef]

21. Ghorbani, M.; Tavakoli-Kakhki, M. Robust stabilizability of fractional order proportional integral controllers for fractional order plants with uncertain parameters: A new value set based approach. J. Vib. Control. 2020, 26, 965-975. [CrossRef]

22. Ghorbani, M. Robust stability analysis of interval fractional-order plants by fractional-order controllers: An approach to reduce additional calculation. Int. J. Gen. Syst. 2020, 50, 1-25. [CrossRef]

23. Monje, C.A.; Vinagre, B.M.; Feliu, V.; Chen, Y.Q. Tuning and auto-tuning of fractional order controllers for industry applications Control. Eng. Pract. 2010, 16, 798-812. [CrossRef]

24. Tepljakov, A.; Petlenkov, E.; Belikov, J. FOPID controller tuning for fractional FOPDT plants subject to design specifications in the frequency domain. In Proceedings of the 2015 European Control Conference (ECC), Linz, Austria, 15-17 July 2015; pp. 3502-3507.

25. Ghorbani, M.; Tavakoli-Kakhki, M. Robust stability analysis of a general class of interval delayed fractional order plants by a general form of fractional order controllers. Math. Methods Appl. Sci. 2020, 44, 10172-10189. [CrossRef]

26. Ghorbani, M.; Tavakoli-Kakhki, M.; Tepljakov, A.; Petlenkov, E.; Farnam, A.; Crevecoeur, G. Robust Stability Analysis of Interval Fractional-Order Plants with Interval Time delay and General Form of Fractional-Order Controllers. IEEE Control. Syst. Lett. 2021, 6, 1268-1273. [CrossRef]

27. Gao, Z.; Yan, M.; Wei, J. Robust stabilizing regions of fractional-order PD $\mu$ controllers of time-delay fractional-order systems. $J$. Process Control. 2014, 24, 37-47. [CrossRef]

28. Zheng, S.; Li, W. Stabilizing region of $P D \mu$ controller for fractional order system with general interval uncertainties and an interval delay. J. Frankl. Inst. 2018, 355, 1107-1138. [CrossRef]

29. Wu, Z.; Viola, J.; Luo, Y.; Chen, Y.; Li, D. Robust Fractional-Order [Proportional Integral Derivative] Controller Design with Specification Constraints: More Flat Phase Idea. Int. J. Control. 2021, 1-39, accepted. [CrossRef]

30. Kheirizad, I.; Khandani, K.; Jalali, A.A. Stabilisability analysis of high-order unstable processes by fractional-order controllers. Int. J. Control. 2013, 86, 244-252. [CrossRef]

31. Lee, Y.; Lee, J.; Park, S. PID controller tuning for integrating and unstable processes with time delay. Chem. Eng. Sci. 2000, 55, 3481-3493. [CrossRef]

32. Zheng, M.; Huang, T.; Zhang, G. Advanced Robust Control and Dynamics Modeling for Complex Industrial Systems. Complexity 2019. [CrossRef]

33. Baleanu, D.; Machado, J.A.T.; Luo, A.C.J. Fractional Dynamics and Control; Springer Science \& Business Media: Berlin/Heidelberg, Germany, 2011. 